\title{
Rancang Bangun Aplikasi Cross Protocol Email dan SMS
}

\author{
Yosua Y. Y. Syahrir, Xaverius B. N. Najoan, Alicia A. E. Sinsuw \\ Teknik Informatika Universitas Sam Ratulangi Manado, Indonesia. \\ yosuasyahrir@gmail.com,xnajoan@unsrat.ac.id, alicia.sinsuw@unsrat.ac.id
}

\begin{abstract}
Abstrak. Teknologi informasi adalah bagian dari media yang digunakan untuk menyampaikan pesan kepada banyak orang. SMS adalah salah satu teknologi telepon seluler yang dapat memudahkan seseorang berkomunikasi dengan orang lain dimanapun berada. Selain SMS, E-mail merupakan sarana yang berperan penting dalam berkomunikasi di dunia maya (internet). SMS dan E-mail merupakan teknologi yang memungkin untuk mengirim dan menerima pesan, tetapi keduanya memiliki platform yang berbeda. Skripsi ini berisi tentang pembuatan aplikasi cross protocol email dan sms dimana dalam proses pembuatannya menggunakan metodologi RAD (Rapid Aplication Development) yang meliputi empat tahan kerja yaitu analisis persyaratan, analisis modeling, desain modeling dan konstruksi. Aplikasi cross protocol ini diharapkan dapat menjadi aplikasi yang dapat digunakan untuk menerima dan mengirim pesan dengan mudah.
\end{abstract}

Kata Kunci : SMS, Email, Cross Protocol, RAD

\section{PENDAHULUAN}

Pada era informasi saat ini bermacam sarana telekomunikasi berkembang dengan sangat pesat dan dengan mudah kita dapatkan baik itu dari telepon kabel, telepon seluler hingga satelit berkembang dengan sangat pesatnya sehingga kita dengan mudah bisa menikmatinya, perkembangan teknologi telekomunikasi yang mengolah memproduksi serta mengirim ataupun menerima segala bentuk pesan komunikasi dimana saja dan kapan saja seolah-olah tanpa mengenal batasan ruang dan waktu dengan SMS.

Perkembangan teknologi telekomunikasi memungkinkan orang mengirim dan menerima informasi dari segala pejuru dunia. Melalui jaringan internet segala informasi dapat diperoleh dengan mudah. Salah-satu teknologi yang paling sering digunakan yaitu pengiriman surat elektronik (e-mail) yang memungkinkan seseorang mengirim data dari tempat yang jauh dengan waktu yang sangat singkat.

SMS dan E-mail merupakan teknologi yang memungkin untuk mengirim dan menerima pesan, tetapi yang membedakan kedua teknologi ini,kedua teknologi ini berbeda platform. SMS merupakan bagian dari platform mobile phone dan E-mail merupakan bagian dari platform jaringan komputer (internet). Beberapa kendala dalam pengiriman SMS bisa terjadi karena masalah jaringan dari provider (pemberi layanan) atau ketika mobile phone dari penerima tidak aktif.Hal inilah yang melatar belakangi penulis untuk membuat aplikasi cross platform yang dapat menghubungkan kedua teknologi informasi ini. Diharapkan dengan aplikasi cross platform ini dapat memudahkan para pengguna untuk mengirim dan merima informasi.

\section{LANDASAN TEORI}

A. SMS

SMS adalah merupakan salah satu layanan pesan teks yang dikembangkan dan distandarisasi oleh suatu badan yang bernama ETSI (European Telecommunication Standards Institute) sebagian dari pengembangan GSM (Global System for Mobile Communication) Phase 2, yang terdapat pada dokumentasi GSM 03.40 dan GSM 03.38. Fitur SMS ini memungkinkan perangkat Stasiun Seluler Digital (Digital Cellular Terminal, seperti Ponsel) untuk dapat mengirim dan menerima pesan-pesan teks dengan panjang sampai dengan 160 karakter melalui jaringan GSM. SMS dapat dikirimkan ke perangkat stasiun seluler digital lainnya hanya dalam beberapa detik selama berada pada jangkauan pelayanan GSM. Lebih dari sekedar pengiriman pesan biasa, layanan SMS memberikan garansi SMS akan sampai pada tujuan meskipun perangkat yang dituju sedang tidak aktif yang dapat disebabkan karena sedang dalam kondisi mati atau berada di luar jangkauan layanan GSM. [1]

\section{B. SMS Gateway}

SMS Gateway adalah sebuah platform yang menyediakan mekanisme untuk mengirim dan menerima SMS dari peralatan mobile melalui SMSC (Short Message Service Center). SMSC merupakan jaringan telepon seluler yang menangani pengiriman SMS. Jadi, ketika seseorang mengirimkan sebuah pesan SMS melalui ponselnya, SMSC bertugas mengirimkan pesan tersebut ke nomor tujuan. Kita dapat memanfaatkan mekanisme tersebut untuk mengirim SMS melalui komputer, salah satunya yaitu melalui aplikasi berbasis web. ${ }^{[2]}$

\section{Gammu}

Gammu merupakan penghubung (gateway) yang menghubungkan perangkat komputer dengan perangkat handphone, pada penggunaan khusus Gammu dapat digunakan sebagai SMS Gateway. Gammu adalah perpustakaan dan utilitas baris perintah untuk ponsel yang dirilis di bawah GNU GPL versi 2 yang diprakarsai oleh Marcin Wiacek.

Gammu dapat digunakan untuk mengelola berbagai fungsi pada handphone, modem dan perangkat sejenis lain nya. Fungsi-fungsi yang dapat dikelola oleh Gammu antara lain adalah fungsi nomor kontak (Phonebook) dan fungsi SMS. Sehingga gammu merupakan aplikasi yang menghubungkan antara handphone ataupun modem yang nantinya di koneksikan dengan interface komputer untuk menjalankan berbagai macam perintah. ${ }^{[3]}$

\section{SMTP}

SMTP (Simple Mail Transfer Protocol) merupakan salah satu protokol email yang umum digunakan untuk pengiriman email di Internet. Protokol ini dipergunakan 
untuk mengirimkan data dari komputer pengirim ke server email tujuan.

SMTP adalah protokol yang cukup sederhana, berbasis teks dimana protokol ini menyebutkan satu atau lebih penerima email untuk kemudian diverifikasi. Jika penerima email valid, maka email akan segera dikirim. SMTP menggunakan port 25 dan dapat dihubungi melalui program telnet. Agar dapat menggunakan SMTP server lewat nama domain, maka record DNS (Domain Name Server) pada bagian MX (Mail Exchange) digunakan. ${ }^{[5]}$

\section{E. Mysq1}

MySQL adalah Relational Database Management System (RDBMS) yang didistribusikan secara gratis di bawah lisensi General Public License (GPL). Dimana setiap orang bebas untuk meng-gunakan MySQL, namun tidak boleh dijadikan produk turunan yang bersifat closed source atau komersial. MySQL sebenarnya merupakan turunan salah satu konsep utama dalam database sejak lama, yaitu Structured Query Language (SQL). SQL adalah sebuah konsep peng-operasian database, terutama untuk pemilihan atau seleksi dan pemasukan data, yang memungkinkan pengoperasian data dikerjakan dengan mudah secara otomatis. Keandalan suatu sistem database (DBMS) dapat diketahui dari cara kerja optimizer-nya dalam melakukan proses perintah-perintah SQL, yang dibuat oleh user maupun program-program aplikasinya. ${ }^{[6]}$

\section{F. RAD}

RAD merupakan salah satu metode pengembangan suatu sistem informasi dengan waktu yang relative singkat. RAD adalah sebuah strategi pengembangan sistem dimana menekan kecepatan pengembangan melalui keterlibatan user ekstensif dalam kecepatan, iterative (berulang) dan incremental construction dari serangkaian fungsi dari prototype sebuah sistem yang pada akhirnya akan mengalami perubahan secara bertahapmenuju sistem akhir. Gambar 1 menjelaskan alur metodologi pengembangan Rapid Application Development (RAD).

Ada 4 tahapan yang harus dilakukan pada metodologi RAD yaitu analisis persyaratan, analisis modelling, desain modelling, dan konstruksi :

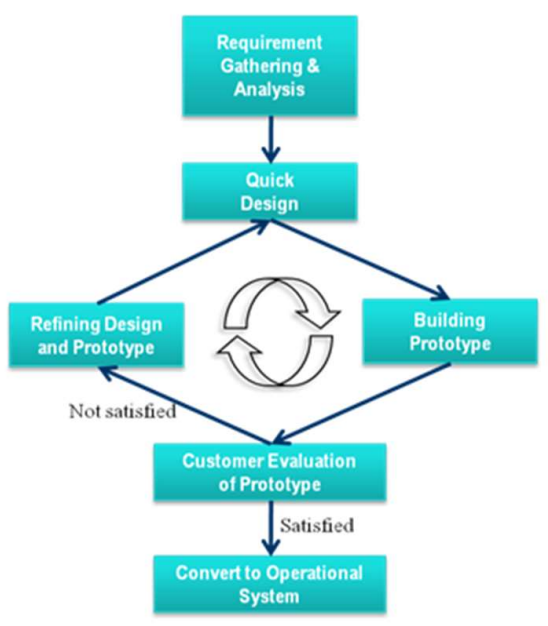

Gambar 1. Metode Pengembangan Perangkat Lunak RAD
A. Analisis Persyaratan

Tahap ini bertujuan untuk mengidentifikasi kebutuhan pengguna, spesifikasi sistem melalui observasi dan pengumpulan data yang dilakukan terhadap stakeholders, sehingga aplikasi yang akan dibuat akan sesuai dengan yang dibutuhkan oleh pengguna.

B. Analisis Modelling

Bertujuan untuk menganalisis sistem yang sedang berjalan dari semua kegiatan yang terjadi pada sistem. Pada tahap ini, ada 2 tools UML yaitu usecase diagram dan acivity diagram yang berfungsi untuk menggambarkan proses yang terjadi dalam sistem yang sedang berjalan.

C. Desain Modelling

Bertujuan untuk melakukan perancangan sistem melalui analisis kebutuhan dan persyaratan dari pengguna yang telah dilakukan sebelumnya. Pada tahap ini tools UML yang digunakan yaitu usecase diagram, activity diagram, sequence diagram.

D. Konstruksi

Tahap ini akan menunjukan platform, hardware, software, batasan implementasi, dan pengujian aplikasi yang telah dibangun apakah sudah sesuai dengan kebutuhan users dan spesifikasi persyaratan yang sebelumnya telah dianalisis. Bagian ini menggunakan tools UML. ${ }^{[7]}$

\section{METOLOGI PENELITIAN}

A. Analisis Persyaratan

Gambar 2 dan 3 menjelaskan tentang arsitektur system dari aplikasi cross protocol.

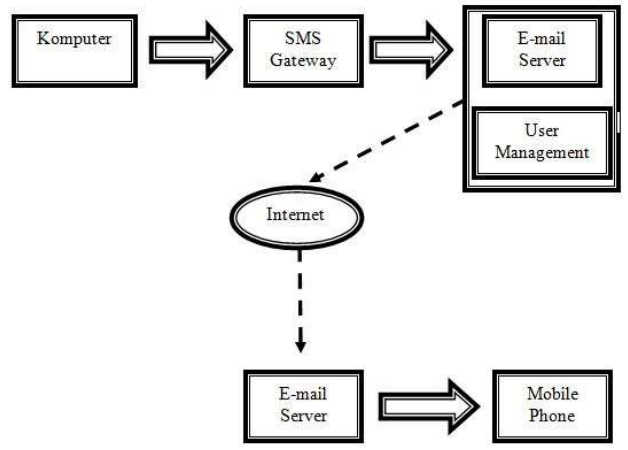

Gambar 2. Rancangan sistem pengiriman SMS ke E-mail

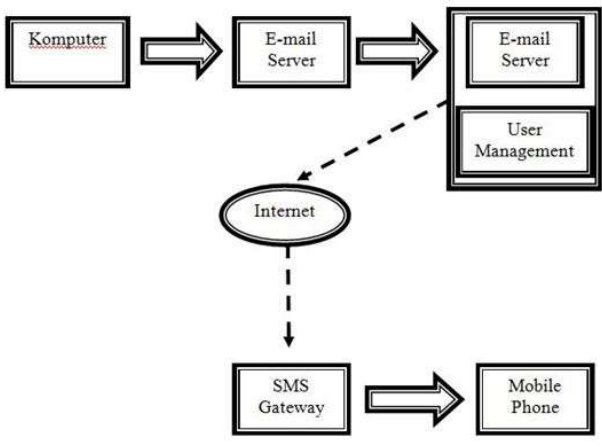

Gambar 3. Rancangan sistem pengiriman E-mail ke SMS 


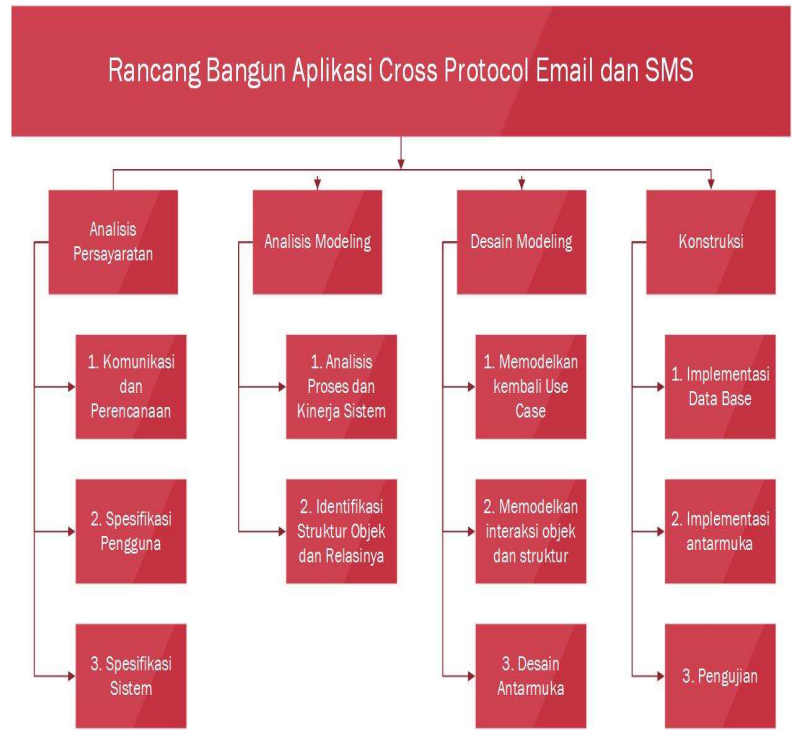

Gambar 4. Rencana kerja penelitian

Gambar 4 merupakan gambar rencana kerja penelitian dari aplikasi cross protocol email dan sms. Rencana kerja ini terdiri dari 4 fase dan masing-masing fase memiliki beberapa tahapan.

\section{B. Analisis Modeling}

Fase berikutnya adalah fase analisis modeling yang bertujuan menganalisis semua kegiatan dalam arsitektur sistem secara keseluruhan dengan cara identifikasi dan abstraksi sistem yang mendasar. Proses yang dilakukan dimulai dari mengidentifikasi aktor dan use case dengan merancang aplikasi yang akan dikembangkan, menggambarkan aliran control untuk mengetahui hubungan aktor dan objek, menggambarkan komunikasi antar objek dan aktor, menggambarkan perubahan keadaan suatu objek pada aplikasi kelas tertentu, memodelkan prilaku use case serta objek pada aplikasi dan menggambarkan perubahan suatu objek pada kelas tertentu.

Aplikasi ini memiliki satu actor yaitu admin. Admin dapat mengatur database dengan menambah data contact, edit data contact, dan hapus data contact, hapus data inbox dan hapus data outbox. Admin dapat mengirimkan email dan pesan yang baru. Tabel 1. Daftar pengguna dan tanggungjawabnya

Tabel 1. Daftar pengguna dan tanggung jawabnya

\begin{tabular}{|l|ll|}
\hline Aktor & \multicolumn{3}{|l|}{ Tugas dan Tanggung Jawab } \\
\hline Admin & 1. & $\begin{array}{l}\text { Mengatur database berupa } \\
\text { penambahan data contact, edit data }\end{array}$ \\
$($ Web App & & $\begin{array}{l}\text { contact, dan hapus data contact, } \\
\text { hapus data inbox dan hapus data } \\
\text { - Server }\end{array}$ \\
side $)$ & outbox. \\
& Mengirim Email dan Pesan \\
\hline
\end{tabular}

\section{Desain Modeling}

Use case diagram menggambarkan hubungan antara aktor dan sistem. Adapun aktor dalam aplikasi Cross Protocol Email dan SMS adalah admin. Gambar 5 adalah use case diagram dari aplikasi cross protocol email dan sms.

\section{Konstruksi}

Fase konstruksi ini merupakan tahapan pembuatan aplikasi yang mengacu pada tahapan sebelumnya dimana untuk menunjukan platform, hardware dan software yang digunakan serta batasan dalam implementasi dan menguji performansi dari aplikasi yang akan dikembangkan. Tahap konstruksi dapat dilihat pada bab IV.

\section{HASIL DAN PEMBAHASAN}

\section{A. Implementasi Database}

Pembuatan aplikasi cross protocol ini menggunakan server localhost dan database MySQL dengan nama database smsin, dalam menejemen database menggunakan phpMyAdmin yang dapat dilihat pada gambar 6 .

Struktur database pada gambar 6 terdapat 12 tabel yaitu daemons, gammu, inbox, message, outbox, outbox_multipart, pbk, pbk_groups, phones, sentitems, sent_msg, dan user.

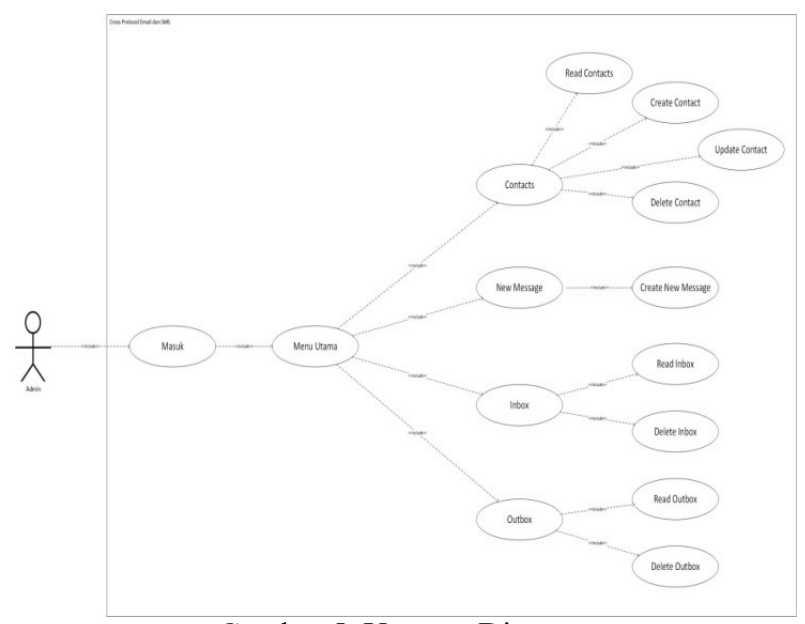

Gambar 5. Usecase Diagram

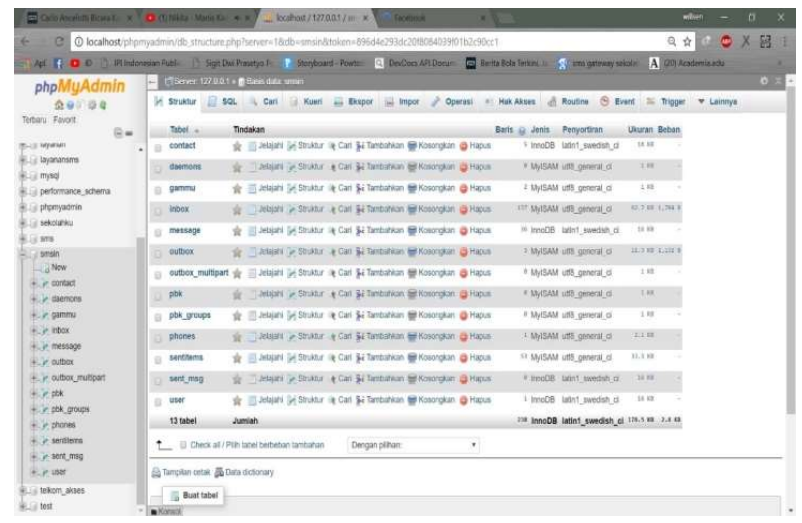

Gambar 6. Implementasi database 


\section{B. Implementasi Antarnuka}

Berikut ini adalah penjelasan mengenai penerapan antarmuka aplikasi Cross Protocol Email dan SMS, pertama-tama admin menjalankan aplikasi dan melakukan login terlebih dahulu.

Gambar 7 Merupakan tampilan dari halaman contacts. Halaman ini berisi data nama, no handphone, dan email.

Gambar 8 Merupakan tampilan dari halaman new message. Pada halaman ini admin dapat mengirimkan email dan sms dengan memilih contact tujuan dan mengisi subject serta isi pesan.

Gambar 9 Merupakan halaman inbox. Pada halaman ini admin dapat melihat email dan sms yang masuk. Halaman ini juga mengijinkan admin untuk menghapus inbox.

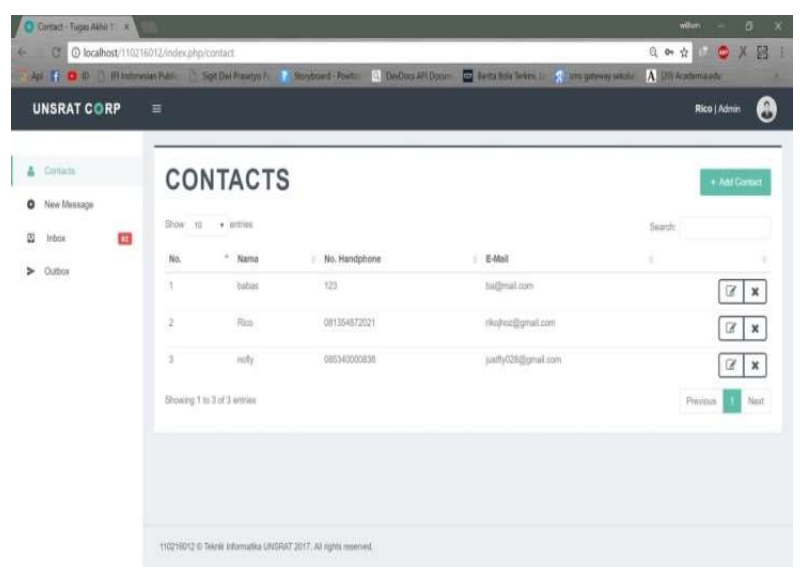

Gambar 7. Tampilan Contacts
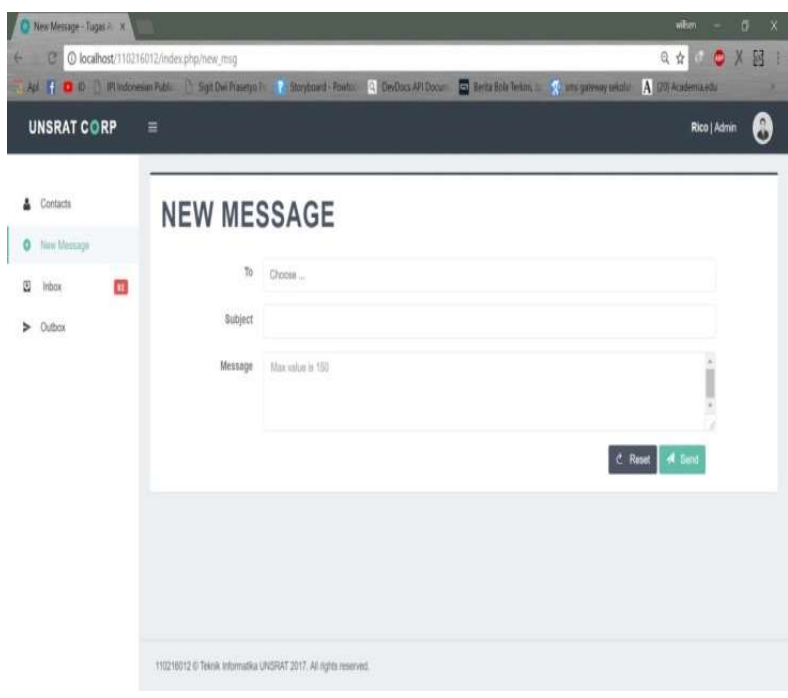

Gambar 8. New Message

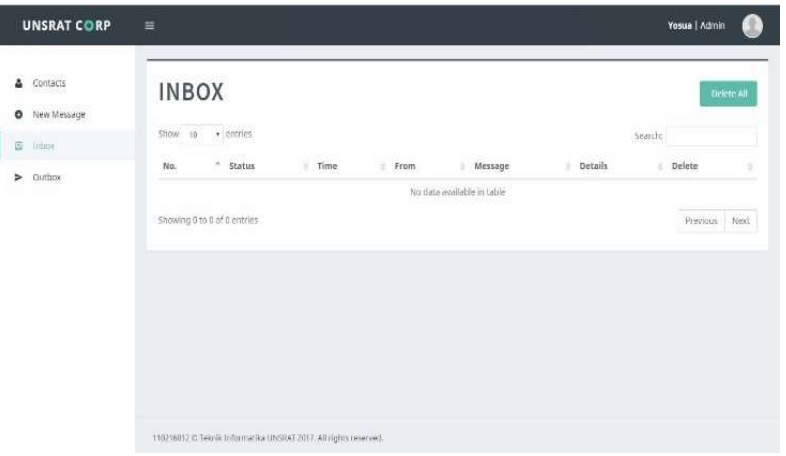

Gambar 9. Inbox

Gambar 9 Merupakan tampilan dari halaman outbox. Pada halaman ini admin dapat melihat pesan terkirim dan juga dapat menghapus pesan terkirim.

\section{Pengujian}

Pada tahap aplikasi ini hanya diterapkan pada pengujian blackbox. Pengujian pada aplikasi meliputi Testing Login, Create, Read, Update, dan Delete. Untuk penjelasan hasil pengujian yang dilakukan dapat dilihat pada Tabel 2.

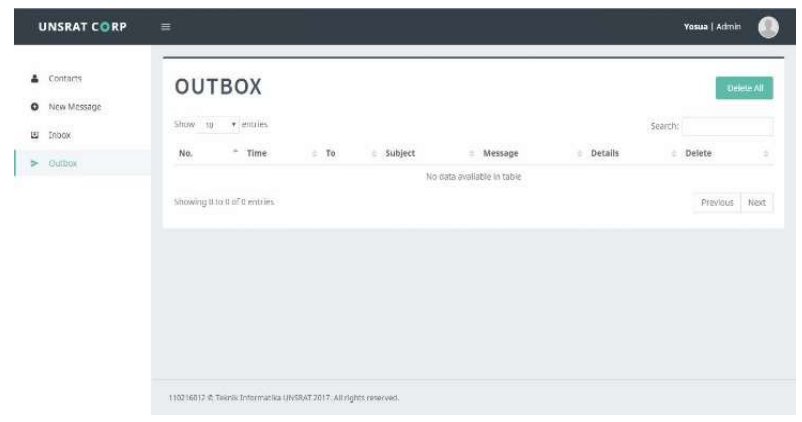

Gambar 10. Outbox

Tabel 2. Tabel Pengujian Aplikasi

\begin{tabular}{|l|}
\hline Titik Pemeriksaan \\
\hline Testing Login \\
\hline Apakah aplikasi dapat membaca username dan pasword? \\
\hline Testing Create \\
\hline Apakah sistem dapat melakukan create? \\
\hline Testing Read \\
\hline Apakah sistem dapat menampilkan data? \\
\hline Testing Update \\
\hline Apakah sistem dapat melakukan update? \\
\hline Testing Delete \\
\hline Apakah sistem dapat melakukan delete? \\
\hline
\end{tabular}


Berdasarkan pengujian sistem yang telah dilakukan, maka dapat disimpulkan bahwa semua fungsi telah berjalan dengan baik. Proses penelitian ini mencakup banyak hal. Bukan hanya sekedar membangun sebuah aplikasi, namun dapat menerapkan metode pengembangan perangkat lunak sebagai acuan dalam membangun sebuah aplikasi yang baik dan benar. Membangun sebuah aplikasi dapat dibuat oleh siapa saja yang memiliki kemampuan dalam pemograman, namun sebagai peneliti yang baik bukan hanya menciptakan sebuah aplikasi namun dapat menerapkan metode pengembangan perangkat lunak untuk menciptakan sebuah aplikasi yang baik dan sesuai prosedur.

Berdasarkan observasi yang dilakukan adanya respon positif yang mendukung dalam pembuatan aplikasi ini dimana aplikasi ini mempermudah dalam penyampaian informasi lewat email dan sms.

\section{KESIMPULAN DAN SARAN}

\section{A. Kesimpulan}

Kesimpulan akhir dari pembuatan aplikasi croos protocol email dan sms ini, adalah sebagai berikut:

1. Aplikasi ini mampu memberikan infomasi dengan cepat lewat email dan sms

2. Metodologi Rapid Application Development (RAD) dapat digunakan untuk membangun aplikasi Cross Protocol Email dan SMS. Aplikasi ini juga dapat berjalan dengan baik pada semua platform web.

B. Saran

Untuk pengembangan selanjutnya diharapkan agar admin mendapatkan notifikasi khusus dari email maupun pesan yang masuk. Aplikasi ini diharapkan dapat digunakan untuk kantor, instansi maupun perusahaan.

\section{DAFTAR PUSTAKA}

[1] Liatmaja Rizka (2013). Pembuatan Aplikasi SMS Gateway Untuk Informasi Akademik Pada Lembaga Bimbingan Belajar Be Excellent Pacitan. Indonesia Journal on Network and Security.

[2] Sardianto (2014). Aplikasi SMS Gateway Untuk Keamanan Sistem Informasi Berbasis WEB. Jurnal Bianglala Informatika, Vol.2 No 1

[3] Pamungkas Canggih Ajika (2015). Pemanfaatan Codeigniter Framework Dalam Membangun SMS Gateway Berbasis Gammu. Politeknik Indonusa Surakarta : Jurnal Informa.

[4] Pamungkas Canggih Ajika (2015). Pemanfaatan Codeigniter Framework Dalam Membangun SMS Gateway Berbasis Gammu. Politeknik Indonusa Surakarta : Jurnal Informa.

[5] Mahardika Adi (2012). Perancangan POP3 Server Dengan Straem Control Transmission Protocol (SCTP) Dalam Proses Pengunduhan Email. Universitas Udayana : Jurnal Elektronik Ilmu Komputer.

[6] Saputra Alhadi (2012). Manajemen Basis Data MySQL Pada Situs FTP Lapan Bandung. Berita Dirgantara, Vol.13 No 4.
[7] Pressman, R.S (2010). Rekayasa Perangkat Lunak buku 1 edisi 7, terjemahan Tim Penerjemah Andi, Yogyakarta: Andi.

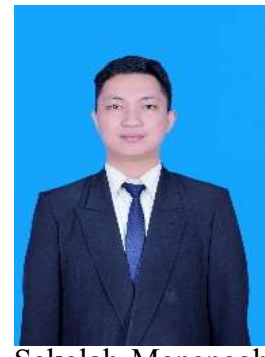

Sekilas dari penulis dengan nama lengkap Yosua Yohanes Yerikho Syahrir, lahir di Manado, Sulawesi Utara. Dengan pendidikan Sekolah Dasar Negeri 1 Kawangkoan. Penulis lalu melanjutkan ke Sekolah Menengah Pertama Negeri 1 Kawangkoan. Lalu ke Yayasan Pendidikan Advent Balikpapan dan Sekolah Menengah Atas Santa Maria Monica Balikpapan. Pada tahun 2011 melanjutkan ke Perguruan Tinggi di Universitas Sam Ratulangi dengan mengambil Jurusan Teknik Informatika. Pada tahun 2016 bulan November, penulis membuat Skripsi demi memenuhi syarat Sarjana (S1) dengan penelitian berjudul Rancang Bangun Aplikasi Cross Protocol Email dan SMS yang dibimbing oleh dua dosen pembimbing yaitu Xaverius B. N. Najoan, ST., MT dan Alicia A. E. Sinsuw, ST., MT sehingga pada tanggal 19 Januari 2018 penulis resmi lulus di Teknik Informatika Universitas Sam Ratulangi Manado menyandang gelar sarjana komputer dengan predikat sangat memuaskan. 